\title{
Vibrational Spectroscopic Studies of Tenofovir Using Density Functional Theory Method
}

\author{
G. R. Ramkumaar, ${ }^{1}$ S. Srinivasan, ${ }^{2}$ T. J. Bhoopathy, ${ }^{1}$ and S. Gunasekaran ${ }^{1}$ \\ ${ }^{1} P G$ and Research Department of Physics, Pachaiyappa's College, Chennai 600030, India \\ ${ }^{2}$ PG and Research Department of Physics, Presidency College, Chennai 600005, India \\ Correspondence should be addressed to G. R. Ramkumaar; gr.ramkumaar@yahoo.com
}

Received 25 June 2012; Revised 23 August 2012; Accepted 3 September 2012

Academic Editor: Isabel Seiquer

Copyright ( 2013 G. R. Ramkumaar et al. This is an open access article distributed under the Creative Commons Attribution License, which permits unrestricted use, distribution, and reproduction in any medium, provided the original work is properly cited.

\begin{abstract}
A systematic vibrational spectroscopic assignment and analysis of tenofovir has been carried out by using FTIR and FT-Raman spectral data. The vibrational analysis was aided by electronic structure calculations-hybrid density functional methods (B3LYP/6311++G(d,p), B3LYP/6-31G(d,p), and B3PW91/6-31G(d,p). Molecular equilibrium geometries, electronic energies, IR intensities, and harmonic vibrational frequencies have been computed. The assignments proposed based on the experimental IR and Raman spectra have been reviewed and complete assignment of the observed spectra have been proposed. UV-visible spectrum of the compound was also recorded and the electronic properties such as HOMO and LUMO energies and $\lambda_{\max }$ were determined by timedependent DFT (TD-DFT) method. The geometrical, thermodynamical parameters, and absorption wavelengths were compared with the experimental data. The B3LYP/6-311++G(d,p)-, B3LYP/6-31G(d,p)-, and B3PW91/6-31G(d,p)-based NMR calculation procedure was also done. It was used to assign the ${ }^{13} \mathrm{C}$ and ${ }^{1} \mathrm{H}$ NMR chemical shift of tenofovir.
\end{abstract}

\section{Introduction}

A recent addition to the antiretroviral armamentarium is the nucleotide analogue tenofovir disoproxil fumarate (Viread), approved for use in the USA and the European Union. Tenofovir is unique among the NRTIs in that it is an acyclic nucleoside phosphonate, analogous to the monophosphate form of the other NRTIs [1]. Tenofovir disoproxil fumarate is an oral prodrug of tenofovir that is rapidly converted into tenofovir upon absorption $[2,3]$. Tenofovir has activity in vitro against both HIV-1 and HIV-2 [4, 5], and in resting and activated $\mathrm{T}$ cells, monocytes and macrophages $[5,6]$. Crossresistance within the NRTI class of drugs has important clinical consequences for patients who are highly treatment experienced, or for those patients in whom primary HIV infection is associated with the transmission of a resistant virus [7].

Literature survey reveals that to the best of our knowledge, neither the complete IR, Raman spectra, nor the quantum mechanical calculations for molecular structure of tenofovir have been reported so far. In the present communication, we report detailed quantum chemical studies of the molecular structure and IR, Raman spectra of tenofovir using basis set. Information about the geometry and structure of the molecule, together with analysis of the IR, Raman spectra, based on frequency and intensity should help in understanding the structural and spectral characteristics. The band assignments have made by assuming $C_{1}$ point group symmetry. Density Functional Theory (DFT) calculations have been performed to support our wave number assignments.

\section{Experimental Details}

The compound tenofovir in powder form was procured from Reputed pharmaceutical company, Chennai, India with more than $98 \%$ purity and was used as such without further purification to record FTIR and FT-Raman spectra. The FTIR spectrum of the compound was recorded in the region 


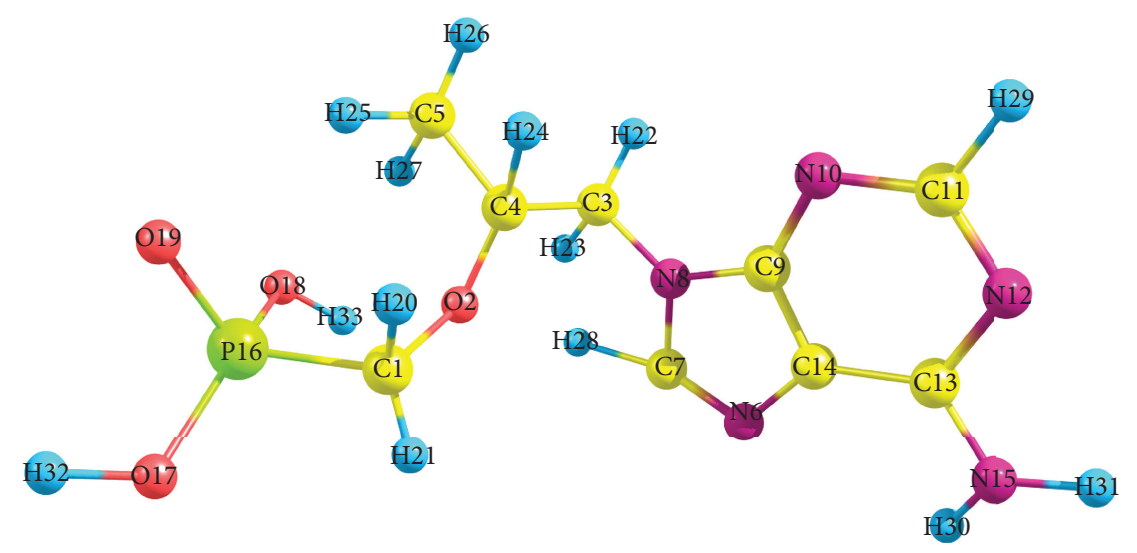

FIgURE 1: Atom numbering scheme of tenofovir.

$4000-450 \mathrm{~cm}^{-1}$ in evacuation mode on Bruker IFS 66V spectrophotometer using $\mathrm{KBr}$ pellet technique (solid phase) with $4.0 \mathrm{~cm}^{-1}$ resolution. The FT-Raman spectrum was recorded using $1064 \mathrm{~nm}$ line of $\mathrm{Nd}$ : YAG laser as excitation wavelength in the region $5000-10 \mathrm{~cm}^{-1}$ on Bruker IFS $66 \mathrm{~V}$ spectrometer equipped with FRA 106 Raman module was used as an accessory. The UV-vis spectral measurements were carried out using a varian cary $5 \mathrm{E}-\mathrm{UV}$-NIR spectrophotometer. The spectral measurements were carried out at sophisticated instrumentation Analysis Facility, IIT, Chennai, India.

\section{Computational Details}

To provide complete information regarding the structural characteristics and the fundamental vibrational modes of tenofovir of B3LYP/6-311++G(d,p), B3LYP/6-31G(d,p), and B3PW91/6-31G(d,p) correlation functional calculations have been carried out. The calculations of geometrical parameters in the ground state were performed using the Gaussian 03 [9] programs, invoking gradient geometry optimization [10] on Intel core i4/2.93 GHZ processor. The geometry optimization was carried out using the initial geometry generated from standard geometrical parameters at B3LYP and B3PW91 methods adopting 6-31G(d,p) and 6-311++G(d,p) basis sets to characterize all stationary points as minima. The optimized structural parameters of the compound tenofovir were used for harmonic vibrational frequency calculations resulting in IR and Raman frequencies together with intensities. In DFT methods, Becke's three parameter exchange-functional (B3) $[11,12]$ combined with gradient-corrected correlation functional of Johnson and Frisch [13] and Burke et al. [1419] by implementing the split-valence polarized 6-31G(d,p) basis set $[20,21]$ have been utilized for the computation of molecular structure optimization, vibrational frequencies, thermodynamic properties, and energies of the optimized structures. The time-dependent density functional theory (TD-DFT) methods were used for the calculation of the UVvis spectra. The IR and UV-vis spectra were calculated and visualized using the SWizard program [22]. The ${ }^{13} \mathrm{C}$ and ${ }^{1} \mathrm{H}$ NMR chemical shifts of the title compound were calculated using the keyword NMR in the DFT-B3LYP and B3PW91 levels.

\section{Results and Discussion}

4.1. Molecular Geometry. To compare the structural parameters of tenofovir and with the available experimental data, they are subjected to geometry optimization in their ground state. For each method, geometry optimizations were performed. The requested convergence on the maximum density matrix was 1026 a.u. the threshold value of the maximum displacement was $0.0018 \mathrm{~A}^{\circ}$ and that of the maximum force was 0.00045 Hartree/Bohr using the Berny analytical gradient optimization routine $[10,23]$. The nature of stationary points is checked by diagonalising the Hessian matrix to determine the number of imaginary wave numbers (zero for local minimum). The optimized bond lengths and bond angles of tenofovir calculated by B3LYP/6-311++G(d,p), B3LYP/631G(d,p), and B3PW91/6-31G(d,p) levels are listed in Table 1 , in accordance with the atom numbering scheme shown in Figure 1. Table 1 shows the comparison of the calculated optimized structure parameters for tenofovir with those experimentally available data [8]. It is observed that most of the optimized structure parameters are slightly larger than the available data values. The bond lengths and bond angles computed by the DFT-B3LYP and B3PW91 levels show excellent agreement with the available computed values.

The bond distance of carbon-carbon in the benzene ring in the range of $1.524 \AA$ confirms the double-bond character and in the range of $1.370 \AA$ supports the single-bond character. The bond distances of $\mathrm{C}-\mathrm{N}$ and $\mathrm{C}-\mathrm{O}$ were in the expected range and agree with the experimental values. Although there is a slight difference between the calculated and experimental structure parameters, the calculated geometric parameters represent a good approximation, and they are the bases for calculating other parameters such as atomic charges, NMR chemical shift values, vibrational modes, and thermodynamic properties.

4.2. Bond-Order Analysis. The bond order of tenofovir is presented in Table 2. Bond order is related to bond strength. The bonds with the higher bond order values have short bond length and vice versa. The bond-order analysis may predict that the weakest bonds may be cleaved preferentially and they may possess a relatively low pi-bond character. From Table 2, 
TABLE 1: Structural parameters of tenofovir calculated by DFT methods.

\begin{tabular}{|c|c|c|c|c|}
\hline \multirow{2}{*}{ Structural parameters } & \multicolumn{4}{|c|}{ Tenofovir } \\
\hline & Experimental [8] & B3LYP/6-311++G(d,p) & B3LYP/6-31G(d,p) & B3PW91/6-31G(d,p) \\
\hline \multicolumn{5}{|c|}{ Internuclear distance $\left(\mathrm{A}^{\circ}\right)$} \\
\hline$R(1-2)$ & 1.402 & 1.412 & 1.427 & 1.421 \\
\hline$R(1-16)$ & 1.856 & 1.837 & 1.841 & 1.838 \\
\hline$R(1-20)$ & 1.113 & 1.096 & 1.096 & 1.096 \\
\hline$R(1-21)$ & 1.113 & 1.093 & 1.095 & 1.096 \\
\hline$R(2-4)$ & 1.402 & 1.443 & 1.444 & 1.437 \\
\hline$R(3-4)$ & 1.523 & 1.532 & 1.531 & 1.527 \\
\hline$R(3-8)$ & 1.470 & 1.456 & 1.454 & 1.448 \\
\hline$R(3-22)$ & 1.113 & 1.091 & 1.093 & 1.093 \\
\hline$R(3-23)$ & 1.113 & 1.092 & 1.095 & 1.095 \\
\hline$R(4-5)$ & 1.523 & 1.524 & 1.526 & 1.521 \\
\hline$R(4-24)$ & 1.113 & 1.095 & 1.098 & 1.099 \\
\hline$R(5-25)$ & 1.113 & 1.091 & 1.093 & 1.093 \\
\hline$R(5-26)$ & 1.113 & 1.094 & 1.095 & 1.095 \\
\hline$R(5-27)$ & 1.113 & 1.094 & 1.096 & 1.096 \\
\hline$R(6-7)$ & 1.369 & 1.310 & 1.312 & 1.310 \\
\hline$R(6-14)$ & 1.366 & 1.382 & 1.385 & 1.380 \\
\hline$R(7-8)$ & 1.315 & 1.381 & 1.383 & 1.378 \\
\hline$R(7-28)$ & 1.100 & 1.080 & 1.081 & 1.082 \\
\hline$R(8-9)$ & 1.369 & 1.379 & 1.381 & 1.377 \\
\hline$R(9-10)$ & 1.345 & 1.337 & 1.339 & 1.337 \\
\hline$R(9-14)$ & 1.384 & 1.396 & 1.398 & 1.396 \\
\hline$R(10-11)$ & 1.340 & 1.335 & 1.337 & 1.335 \\
\hline$R(11-12)$ & 1.352 & 1.341 & 1.343 & 1.340 \\
\hline$R(11-29)$ & 1.100 & 1.086 & 1.088 & 1.089 \\
\hline$R(12-13)$ & 1.349 & 1.343 & 1.346 & 1.343 \\
\hline$R(13-14)$ & 1.376 & 1.408 & 1.411 & 1.410 \\
\hline$R(13-15)$ & 1.266 & 1.354 & 1.356 & 1.350 \\
\hline$R(15-30)$ & 1.050 & 1.006 & 1.007 & 1.006 \\
\hline$R(15-31)$ & 1.050 & 1.007 & 1.008 & 1.006 \\
\hline$R(16-17)$ & 1.615 & 1.617 & 1.619 & 1.616 \\
\hline$R(16-18)$ & 1.615 & 1.626 & 1.619 & 1.614 \\
\hline$R(16-19)$ & 1.480 & 1.484 & 1.486 & 1.484 \\
\hline$R(17-32)$ & 0.942 & 0.965 & 0.969 & 0.967 \\
\hline$R(18-33)$ & 0.942 & 0.965 & 0.972 & 0.972 \\
\hline \multicolumn{5}{|c|}{ Bond angle $\left({ }^{\circ}\right)$} \\
\hline$A(2-1-16)$ & 109.5 & 111.9 & 109.1 & 109.2 \\
\hline$A(2-1-20)$ & 109.4 & 112.5 & 112.1 & 112.2 \\
\hline$A(2-1-21)$ & 109.5 & 108.3 & 108.1 & 108.0 \\
\hline$A(1-2-4)$ & 120.0 & 117.6 & 116.9 & 116.5 \\
\hline$A(16-1-20)$ & 109.4 & 108.0 & 110.1 & 110.2 \\
\hline$A(16-1-21)$ & 109.5 & 107.7 & 108.9 & 108.7 \\
\hline$A(1-16-17)$ & 109.5 & 102.7 & 103.7 & 103.8 \\
\hline$A(1-16-18)$ & 109.4 & 105.2 & 101.1 & 100.5 \\
\hline$A(1-16-19)$ & 109.5 & 117.7 & 116.3 & 116.6 \\
\hline$A(20-1-21)$ & 109.5 & 108.3 & 108.5 & 108.4 \\
\hline$A(2-4-3)$ & 109.5 & 106.5 & 105.9 & 105.9 \\
\hline$A(2-4-5)$ & 109.4 & 111.1 & 112.0 & 112.2 \\
\hline$A(2-4-24)$ & 109.5 & 109.0 & 108.5 & 108.5 \\
\hline$A(4-3-8)$ & 109.5 & 113.0 & 113.2 & 113.2 \\
\hline$A(4-3-22)$ & 109.4 & 109.6 & 109.5 & 109.4 \\
\hline
\end{tabular}


TABle 1: Continued.

\begin{tabular}{|c|c|c|c|c|}
\hline \multirow{2}{*}{ Structural parameters } & \multicolumn{4}{|c|}{ Tenofovir } \\
\hline & Experimental [8] & B3LYP/6-311++G(d,p) & B3LYP/6-31G(d,p) & B3PW91/6-31G(d,p) \\
\hline \multicolumn{5}{|c|}{ Bond angle $\left({ }^{\circ}\right)$} \\
\hline$A(4-3-23)$ & 109.5 & 109.4 & 109.4 & 109.5 \\
\hline$A(3-4-5)$ & 109.4 & 111.5 & 111.9 & 111.8 \\
\hline$A(3-4-24)$ & 109.5 & 108.6 & 108.3 & 108.2 \\
\hline$A(8-3-22)$ & 109.4 & 107.7 & 107.0 & 107.0 \\
\hline$A(8-3-23)$ & 109.5 & 108.4 & 109.1 & 109.2 \\
\hline$A(3-8-7)$ & 127.5 & 128.0 & 128.5 & 128.6 \\
\hline$A(3-8-9)$ & 127.5 & 126.1 & 125.6 & 125.5 \\
\hline$A(22-3-23)$ & 109.5 & 108.6 & 108.5 & 108.4 \\
\hline$A(5-4-24)$ & 109.5 & 110.0 & 110.1 & 110.1 \\
\hline$A(4-5-25)$ & 109.5 & 110.3 & 110.9 & 111.0 \\
\hline$A(4-5-26)$ & 109.4 & 110.3 & 110.3 & 110.3 \\
\hline$A(4-5-27)$ & 109.5 & 110.4 & 110.6 & 110.7 \\
\hline$A(25-5-26)$ & 109.4 & 108.5 & 108.5 & 108.4 \\
\hline$A(25-5-27)$ & 109.5 & 108.8 & 108.2 & 108.2 \\
\hline$A(26-5-27)$ & 109.5 & 108.4 & 108.2 & 108.2 \\
\hline$A(7-6-14)$ & 107.5 & 104.0 & 103.8 & 103.7 \\
\hline$A(6-7-8)$ & 111.8 & 113.9 & 114.0 & 114.0 \\
\hline$A(6-7-28)$ & 124.1 & 125.3 & 125.4 & 125.3 \\
\hline$A(6-14-9)$ & 104.8 & 111.0 & 111.3 & 111.3 \\
\hline$A(6-14-13)$ & 135.0 & 133.0 & 133.0 & 133.0 \\
\hline$A(8-7-28)$ & 124.1 & 120.8 & 120.7 & 120.7 \\
\hline$A(7-8-9)$ & 105.0 & 105.8 & 105.8 & 105.9 \\
\hline$A(8-9-10)$ & 125.7 & 128.1 & 127.9 & 127.8 \\
\hline$A(8-9-14)$ & 110.9 & 105.2 & 105.1 & 105.0 \\
\hline$A(10-9-14)$ & 104.8 & 126.6 & 127.0 & 127.2 \\
\hline$A(9-10-11)$ & 112.6 & 111.6 & 111.2 & 111.0 \\
\hline$A(9-14-13)$ & 120.3 & 116.0 & 115.8 & 115.6 \\
\hline$A(10-11-12)$ & 128.1 & 128.4 & 128.8 & 128.9 \\
\hline$A(10-11-29)$ & 115.9 & 116.1 & 115.9 & 115.9 \\
\hline$A(12-11-29)$ & 115.9 & 115.4 & 115.3 & 115.2 \\
\hline$A(11-12-13)$ & 118.1 & 118.7 & 118.4 & 118.4 \\
\hline$A(12-13-14)$ & 117.6 & 118.7 & 118.9 & 118.9 \\
\hline$A(12-13-15)$ & 121.2 & 118.9 & 118.8 & 118.8 \\
\hline$A(14-13-15)$ & 121.2 & 122.4 & 122.3 & 122.3 \\
\hline$A(13-15-30)$ & 120.0 & 119.9 & 119.0 & 119.5 \\
\hline$A(13-15-31)$ & 120.0 & 118.7 & 117.9 & 118.3 \\
\hline$A(30-15-31)$ & 120.0 & 119.9 & 119.4 & 120.0 \\
\hline$A(17-16-18)$ & 109.4 & 102.8 & 101.8 & 102.2 \\
\hline$A(17-16-19)$ & 109.5 & 116.9 & 114.2 & 113.9 \\
\hline$A(16-17-32)$ & 120.0 & 114.2 & 109.7 & 109.3 \\
\hline$A(18-16-19)$ & 109.5 & 113.1 & 117.5 & 117.6 \\
\hline$A(16-18-33)$ & 120.0 & 111.9 & 108.6 & 107.9 \\
\hline
\end{tabular}

it is noted that bond between $\mathrm{O} 2-\mathrm{C} 4$ possess relatively low pibond character with low-bond-order value of 0.848 obtained DFT-B3LYP method, respectively. The P16-O19 bond order values are in the range 1.947, which depict the double bond character, while the C4-C5 and N8-C9 bond-order value is approximately unity, which shows the single-bond character. The optimized geometrical values are in support of the bondorder analysis. 


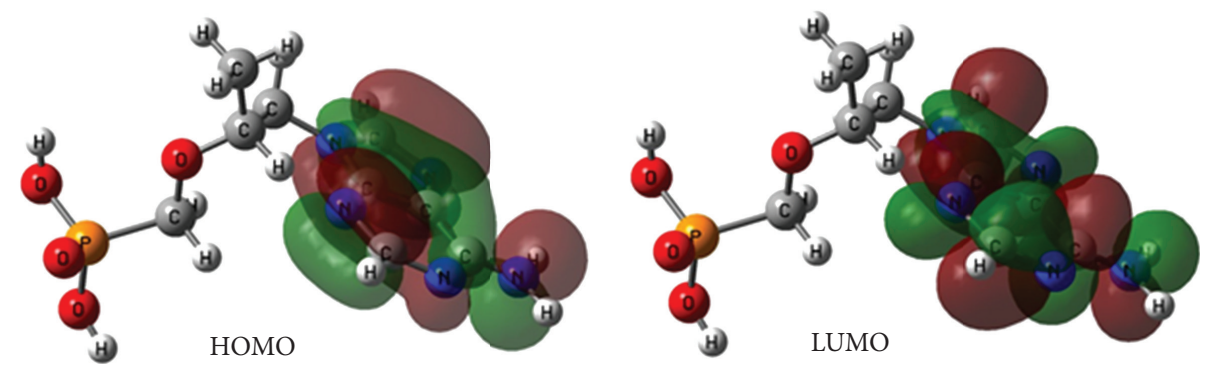

Figure 2: The HOMO and LUMO of tenofovir.

TABLE 2: Bond orders of tenofovir.

\begin{tabular}{|c|c|}
\hline Bond order & B3LYP/6-31G(d,p) \\
\hline $\mathrm{C} 1-\mathrm{O} 2$ & 0.913 \\
\hline $\mathrm{C} 1-\mathrm{P} 16$ & 0.845 \\
\hline $\mathrm{C} 1-\mathrm{H} 20$ & 0.921 \\
\hline $\mathrm{C} 1-\mathrm{H} 21$ & 0.909 \\
\hline $\mathrm{O} 2-\mathrm{C} 4$ & 0.848 \\
\hline $\mathrm{C} 3-\mathrm{C} 4$ & 0.923 \\
\hline $\mathrm{C} 3-\mathrm{N} 8$ & 0.862 \\
\hline $\mathrm{C} 3-\mathrm{H} 22$ & 0.94 \\
\hline $\mathrm{C} 3-\mathrm{H} 23$ & 0.934 \\
\hline C4-C5 & 1.001 \\
\hline $\mathrm{C} 4-\mathrm{H} 24$ & 0.815 \\
\hline C5-H25 & 0.96 \\
\hline $\mathrm{C} 5-\mathrm{H} 26$ & 0.954 \\
\hline C5-H27 & 0.956 \\
\hline N6-C7 & 1.517 \\
\hline N6-C14 & 1.138 \\
\hline C7-N8 & 1.185 \\
\hline $\mathrm{C} 7-\mathrm{H} 28$ & 0.949 \\
\hline N8-C9 & 1.04 \\
\hline C9-N10 & 1.123 \\
\hline C9-C14 & 1.311 \\
\hline N10-C11 & 1.464 \\
\hline $\mathrm{C} 11-\mathrm{N} 12$ & 1.396 \\
\hline C11-H29 & 0.948 \\
\hline N12-C13 & 1.3 \\
\hline C13-C14 & 1.187 \\
\hline C13-N15 & 1.109 \\
\hline N15-H30 & 0.876 \\
\hline N15-H31 & 0.878 \\
\hline P16-O17 & 1.021 \\
\hline P16-O18 & 1.038 \\
\hline P16-O19 & 1.947 \\
\hline O17-H32 & 0.856 \\
\hline O18-H33 & 0.853 \\
\hline
\end{tabular}

4.3. Electronic Properties. The energies of four important molecular orbitals of tenofovir: the highest and second highest occupied MOs (HOMO and HOMO-1), the lowest and the second lowest unoccupied MOs (LUMO and LUMO+1) were calculated and are presented in Table 3. The lowest singlet $\rightarrow$ singlet spin-allowed excited states of tenofovir were taken into account for the TD-DFT calculation in order to investigate the properties of electronic absorption. The experimental $\lambda_{\max }$ values are obtained from the UV/visible spectra recorded in methanol as reported earlier [24]. The calculations were also performed with methanol solvent effect. The calculated absorption wavelengths $\left(\lambda_{\max }\right)$, oscillator strength, excitation energies, and the experimental wavelengths are also given in Table 3. The energy gap between HOMO and LUMO is a critical parameter in determining molecular electrical transport properties [25]. In the electronic absorption spectrum of tenofovir, there are three absorption bands with a maximum 268.67, 250, and $230.69 \mathrm{~nm}$. The strong absorption band $268.67 \mathrm{~nm}$ is caused by the $n-\pi^{*}$ and the other two moderately intense bands are due to $\pi-\pi^{*}$ transitions. The $\pi-\pi^{*}$ transitions are expected to occur relatively at lower wavelength, due to the consequence of the extended aromaticity of the benzene ring. The HOMO and LUMO of tenofovir are represented in Figure 2.

4.4. Natural Population Analysis. The calculation of effective atomic charges plays an important role in the application of quantum mechanical calculations to molecular systems. Our interest here is in the comparison of different methods (B3LYP and B3PW91) to describe the electron distribution in tenofovir as broadly as possible, and to assess the sensitivity of the calculated charges to changes in the choice of the quantum chemical method. The calculated natural atomic charge values from the natural population analysis (NPA) and Mulliken population analysis (MPA) procedures using the B3LYP/6-311++G(d,p), B3LYP/6-31G(d,p), and B3PW91/6-31G(d,p) methods are listed in Table 4. The NPA from the natural-bonding orbital (NBO) method is better than the MPA scheme. Table 4 compares the atomic charge site of tenofovir from both MPA and NPA methods. The NPA of tenofovir shows that the presence of three oxygen atoms in the nitrate moiety $[\mathrm{O} 17=-0.979$ (B3LYP/6$311++\mathrm{G}(\mathrm{d}, \mathrm{p})),-1.023(\mathrm{~B} 3 \mathrm{LYP} / 6-31 \mathrm{G}(\mathrm{d}, \mathrm{p}))$ and -1.023 (B3PW91/6-31G(d,p)); O18 = -0.983 (B3LYP/6-311++ $\mathrm{G}(\mathrm{d}, \mathrm{p})),-1.027$ (B3LYP/6-31G(d,p)) and -1.027 (B3PW91/ 6-31G(d,p)); O19 = -1.070 (B3LYP/6-311++G(d,p)), -1.092 (B3LYP/6-31G(d,p)) and -1.087 (B3PW91/6-31G(d,p))] imposes large positive charges on the Phosphorus atom $[\mathrm{P} 16=2.265(\mathrm{~B} 3 \mathrm{LYP} / 6-311++\mathrm{G}(\mathrm{d}, \mathrm{p})), 2.388(\mathrm{~B} 3 \mathrm{LYP} / 6-$ $31 \mathrm{G}(\mathrm{d}, \mathrm{p})$ and 2.373 (B3PW91/6-31G(d,p))]. However, the 
TABLE 3: Experimental and calculated absorption wavelength $(\lambda)$, excitation energies $(E)$, oscillator strength $(f)$, and frontier orbital energies of tenofovir by TD-DFT method.

\begin{tabular}{lccccccc}
\hline$\lambda$ & $\lambda$ & $E$ & $f$ & Assignment & $\begin{array}{c}E_{\mathrm{HOMO}} \\
(\mathrm{eV})\end{array}$ & $\begin{array}{c}E_{\mathrm{LUMO}} \\
(\mathrm{eV})\end{array}$ & $\begin{array}{c}E_{\mathrm{HOMO}-1} \\
(\mathrm{eV})\end{array}$ \\
\hline 268.67 & $(\mathrm{Cal} . ; \mathrm{nm})$ & $(\mathrm{eV})$ & $\begin{array}{c}E_{\mathrm{LUMO}+1} \\
(\mathrm{eV})\end{array}$ \\
250 & 286.26 & 4.3311 & 0.0004 & $n \rightarrow \pi^{*}$ & & & \\
230.69 & 252.03 & 4.9194 & 0.0019 & $\pi \rightarrow \pi^{-*}$ & -5.95 & -0.6631 & -5.9882 \\
\hline
\end{tabular}

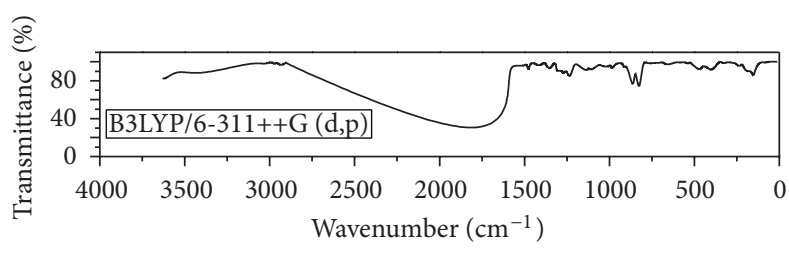

(a)

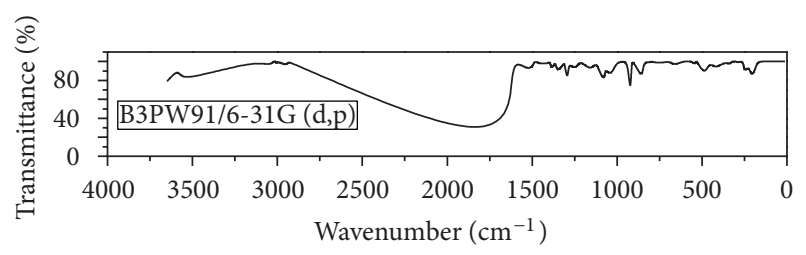

(c)

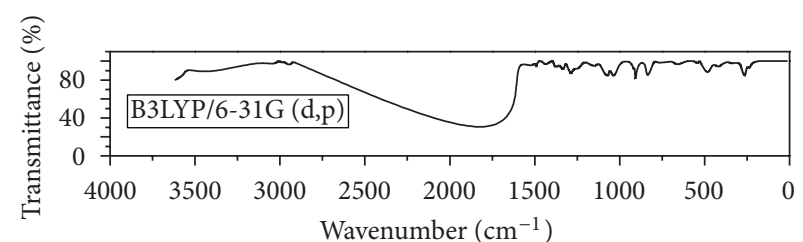

(b)

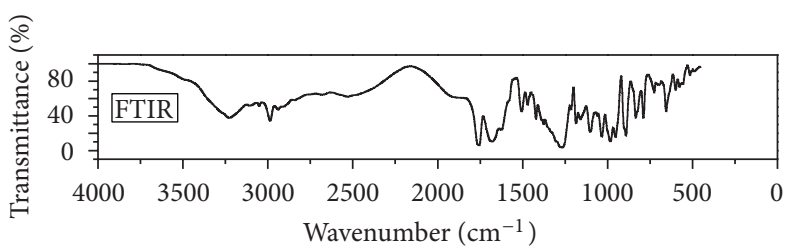

(d)

FIGURE 3: Theoretical and experimental IR spectrum of tenofovir.

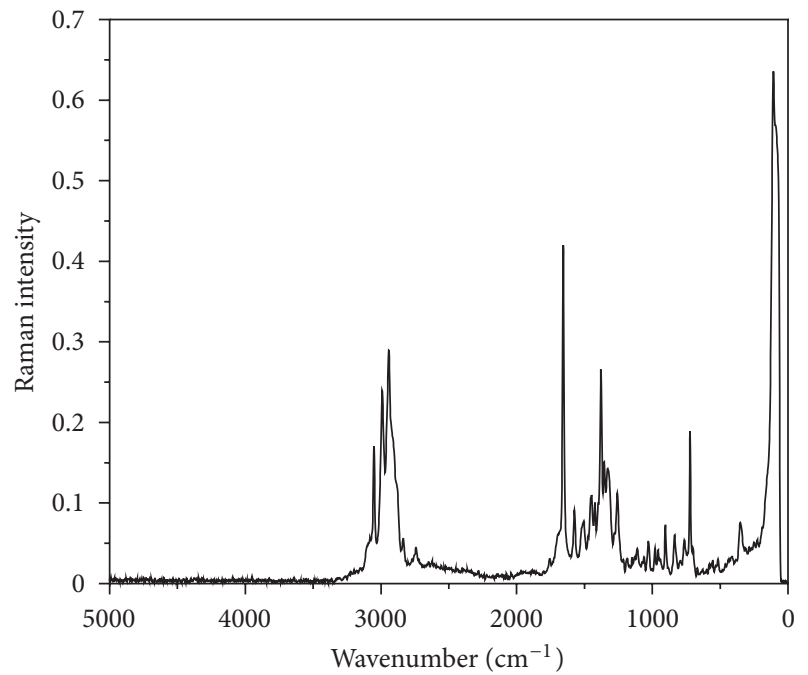

FIGURE 4: FT-Raman spectrum of tenofovir.

nitrogen atoms N6, N8, N10, and N12 possess large negative charges, resulting in the positive charges on the carbon atoms C7, C9, C11, C13, and C14. Moreover, there is no difference in charge distribution observed on all hydrogen atoms except the $\mathrm{H} 30, \mathrm{H} 31, \mathrm{H} 32$, and $\mathrm{H} 33$ hydrogen atoms. The positive charge on $\mathrm{H} 30, \mathrm{H} 31, \mathrm{H} 32$, and $\mathrm{H} 33$ hydrogen atoms is due to the negative charge accumulated on the N15, O17, and O18 atoms.

4.5. Vibrational Spectra. The experimental FTIR, calculated (B3LYP, B3PW91) and FT-Raman and vibrational spectra were shown in Figures 3 and 4 . Since the calculated vibrational wave numbers were known to be higher than the experimental ones, they were scaled down by the wavenumber linear scaling procedure of Yoshida et al. [26] by using the expression:

$$
v_{\mathrm{obs}}=\left(1.0087-0.0000163 v_{\text {calc. }}\right) v_{\text {calc. }} .
$$

Comparison of the frequencies calculated at B3LYP and B3PW91 with experimental values (Table 5) reveals the overestimation of the calculated vibrational modes due to the neglect anharmonicity in real system. According to the theoretical calculations, tenofovir has a nonplanar structure of $\mathrm{C}_{1}$ point group symmetry. The molecule has 33 atoms and 93 normal modes of vibration active in both IR and Raman. Since the title molecule possess $C_{1}$ point group symmetry, all the modes of vibration belong to A species only. The Chemcraft program was used to display the vibrational modes. Vibrational wave number assignments were made on the basis of combining the results of Chemcraft program with the symmetry, and taking the atomic displacements into consideration based on the frequency calculation and also made in analogy with the structurally related molecules. 
TABLE 4: Natural atomic charges of tenofovir.

\begin{tabular}{|c|c|c|c|c|c|c|}
\hline \multirow{2}{*}{$\begin{array}{l}\text { Atom with } \\
\text { numbering }\end{array}$} & \multicolumn{3}{|c|}{ MPA } & \multicolumn{3}{|c|}{ NPA } \\
\hline & $\begin{array}{c}\text { B3LYP/ } \\
6-311++G(d, p)\end{array}$ & $\begin{array}{c}\text { B3LYP/ } \\
6-31 \mathrm{G}(\mathrm{d}, \mathrm{p})\end{array}$ & $\begin{array}{c}\text { B3PW91/ } \\
6-31 G(\mathrm{~d}, \mathrm{p})\end{array}$ & $\begin{array}{c}\text { B3LYP/ } \\
6-311++G(d, p)\end{array}$ & $\begin{array}{c}\text { B3LYP/ } \\
6-31 \mathrm{G}(\mathrm{d}, \mathrm{p})\end{array}$ & $\begin{array}{r}\text { B3PW91/ } \\
6-31 G(\mathrm{~d}, \mathrm{p}) \\
\end{array}$ \\
\hline $\mathrm{C} 1$ & -0.153 & -0.124 & -0.190 & -0.362 & -0.493 & -0.511 \\
\hline $\mathrm{O} 2$ & -0.527 & -0.508 & -0.506 & -0.617 & -0.599 & -0.596 \\
\hline $\mathrm{C} 3$ & -0.059 & -0.077 & -0.122 & -0.184 & -0.287 & -0.305 \\
\hline $\mathrm{C} 4$ & 0.163 & 0.133 & 0.090 & 0.050 & 0.044 & 0.035 \\
\hline C5 & -0.347 & -0.333 & -0.404 & -0.577 & -0.703 & -0.729 \\
\hline N6 & -0.539 & -0.587 & -0.602 & -0.516 & -0.510 & -0.510 \\
\hline $\mathrm{C} 7$ & 0.285 & 0.247 & 0.242 & 0.248 & 0.205 & 0.198 \\
\hline N8 & -0.513 & -0.479 & -0.516 & -0.412 & -0.393 & -0.391 \\
\hline C9 & 0.512 & 0.511 & 0.542 & 0.383 & 0.369 & 0.366 \\
\hline $\mathrm{N} 10$ & -0.524 & -0.564 & -0.596 & -0.583 & -0.587 & -0.586 \\
\hline $\mathrm{C} 11$ & 0.227 & 0.226 & 0.217 & 0.313 & 0.264 & 0.257 \\
\hline $\mathrm{N} 12$ & -0.521 & -0.548 & -0.568 & -0.558 & -0.557 & -0.556 \\
\hline $\mathrm{C} 13$ & 0.480 & 0.561 & 0.594 & 0.401 & 0.418 & 0.412 \\
\hline $\mathrm{C} 14$ & 0.195 & 0.248 & 0.223 & -0.002 & 0.007 & 0.004 \\
\hline N15 & -0.639 & -0.662 & -0.709 & -0.727 & -0.788 & -0.796 \\
\hline P16 & 1.072 & 1.054 & 1.081 & 2.265 & 2.388 & 2.373 \\
\hline O17 & -0.556 & -0.548 & -0.564 & -0.979 & -1.023 & -1.023 \\
\hline $\mathrm{O} 18$ & -0.555 & -0.552 & -0.567 & -0.983 & -1.027 & -1.027 \\
\hline O19 & -0.550 & -0.549 & -0.554 & -1.070 & -1.092 & -1.087 \\
\hline $\mathrm{H} 20$ & 0.137 & 0.129 & 0.156 & 0.204 & 0.238 & 0.247 \\
\hline $\mathrm{H} 21$ & 0.156 & 0.089 & 0.112 & 0.170 & 0.199 & 0.207 \\
\hline $\mathrm{H} 22$ & 0.153 & 0.128 & 0.157 & 0.208 & 0.248 & 0.257 \\
\hline $\mathrm{H} 23$ & 0.123 & 0.128 & 0.155 & 0.208 & 0.244 & 0.253 \\
\hline $\mathrm{H} 24$ & 0.113 & 0.223 & 0.260 & 0.259 & 0.295 & 0.301 \\
\hline $\mathrm{H} 25$ & 0.165 & 0.124 & 0.151 & 0.219 & 0.254 & 0.263 \\
\hline $\mathrm{H} 26$ & 0.116 & 0.104 & 0.130 & 0.204 & 0.239 & 0.249 \\
\hline $\mathrm{H} 27$ & 0.106 & 0.095 & 0.120 & 0.194 & 0.225 & 0.234 \\
\hline $\mathrm{H} 28$ & 0.122 & 0.127 & 0.159 & 0.203 & 0.238 & 0.246 \\
\hline $\mathrm{H} 29$ & 0.100 & 0.109 & 0.141 & 0.179 & 0.225 & 0.232 \\
\hline $\mathrm{H} 30$ & 0.288 & 0.304 & 0.326 & 0.419 & 0.445 & 0.452 \\
\hline $\mathrm{H} 31$ & 0.280 & 0.289 & 0.311 & 0.411 & 0.438 & 0.445 \\
\hline H32 & 0.353 & 0.349 & 0.362 & 0.514 & 0.537 & 0.541 \\
\hline $\mathrm{H} 33$ & 0.340 & 0.353 & 0.366 & 0.520 & 0.541 & 0.545 \\
\hline
\end{tabular}

The $\mathrm{CH}$ and $\mathrm{OH}$ stretching modes are expected to be observed at the high wave number region. The $\mathrm{CH}$ stretching bands are observed between $3106 \mathrm{~cm}^{-1}$ and $3051 \mathrm{~cm}^{-1}$ in FTIR spectrum. The $\mathrm{CH}$ stretching modes in the ring and methylene groups were identified and their effect in tenofovir was examined. Let us start considering the contribution of theoretical methods B3LYP/6-311++G(d,p), B3LYP/6$31 \mathrm{G}(\mathrm{d}, \mathrm{p})$ and B3PW91/6-31G(d,p), the OH stretching mode is predicted at $3650 \mathrm{~cm}^{-1}, 3583 \mathrm{~cm}^{-1}$ in B3PW91 and $3620 \mathrm{~cm}^{-1}, 3563 \mathrm{~cm}^{-1}$ in B3LYP and $3629 \mathrm{~cm}^{-1}, 3619 \mathrm{~cm}^{-1}$ in B3LYP/6-311++G(d,p) after scaling. This OH stretching mode is affected in the presence of water molecules. The $\mathrm{CH}_{2}$ scissoring and wagging mode was also identified. A major coincidence of theoretical values with that of experimental evaluations is found in the asymmetric and symmetric vibrations of the methylene $\left(-\mathrm{CH}_{2}-\right)$ moiety. The $-\mathrm{CH}_{2}-$ wagging mode at $1330 \mathrm{~cm}^{-1}$ in FT-Raman deviates positively by $20 \mathrm{~cm}^{-1}$ from the reported value of $1350 \mathrm{~cm}^{-1}$ [25] and theoretically coincide with $1321 \mathrm{~cm}^{-1}$ in B3LYP and $1334 \mathrm{~cm}^{-1}$ in B3PW91. The vibrational frequency $1455 \mathrm{~cm}^{-1}$ in B3LYP and $1449 \mathrm{~cm}^{-1}$ in B3PW91 is found neater to FTIR- $\mathrm{CH}_{2}-$ scissoring mode of $1447 \mathrm{~cm}^{-1}$.

The scaled $\mathrm{NH}_{2}$ asymmetric and symmetric stretching vibrations of theoretical values are $3570 \mathrm{~cm}^{-1}$ and $3456 \mathrm{~cm}^{-1}$. The computed $\mathrm{NH}_{2}$ scissoring vibration at $1588 \mathrm{~cm}^{-1}$ in 

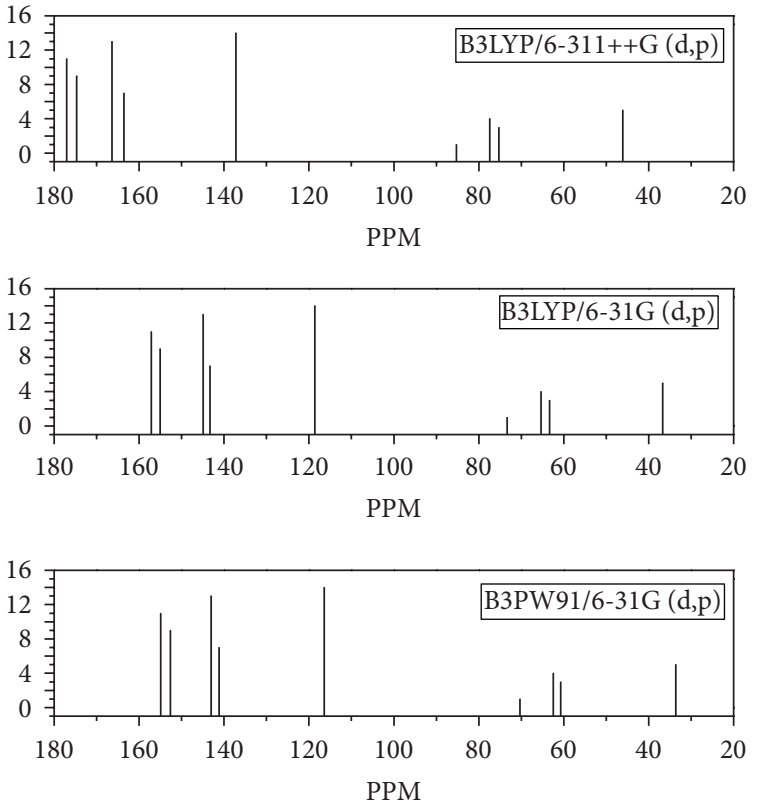

(a)
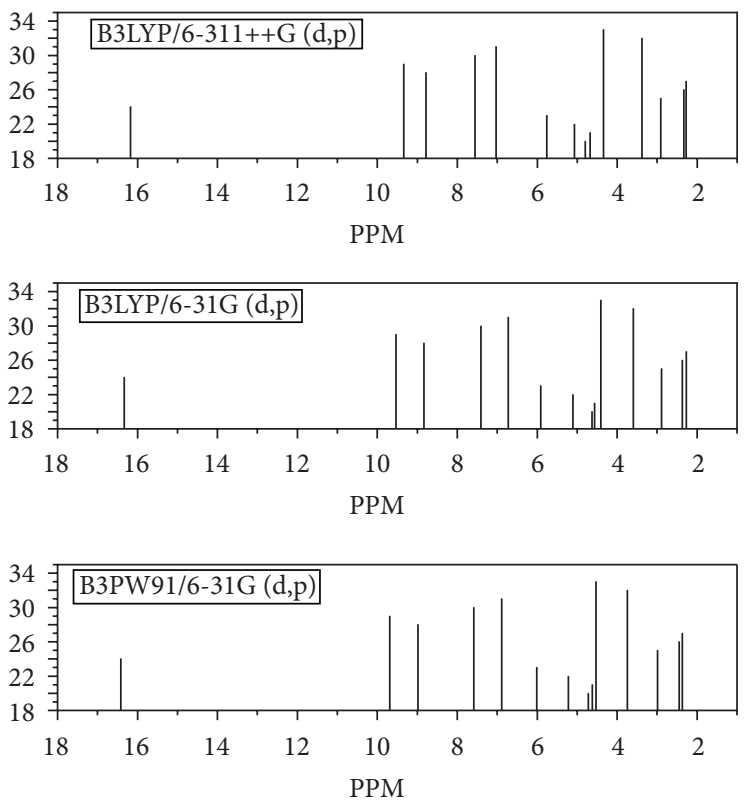

(b)

FIGURE 5: (a) ${ }^{13} \mathrm{C}$ NMR spectrum of tenofovir. (b) ${ }^{1} \mathrm{H}$ NMR spectrum of tenofovir.

B3LYP and $1595 \mathrm{~cm}^{-1}$ in B3PW91 is in agreement with the expected characteristic value, $1600 \mathrm{~cm}^{-1}[27,28]$. In the presence of water molecules in the tenofovir, the NH stretching vibrations were red shifted by $10 \mathrm{~cm}^{-1}$. But however, the $\mathrm{NH}_{2}$ scissoring mode does not get affected. Notice that the most evident discrepancies between the experimental and calculated spectra are associated with the stretching modes showing the effect of water molecules. List of selected observed and calculated bands of tenofovir was presented in Table 5.

\section{5. ${ }^{13} \mathrm{C}$ and ${ }^{1} \mathrm{H}$-NMR Chemical Shift Assignment}

The ${ }^{13} \mathrm{C}$ and ${ }^{1} \mathrm{H}$ NMR simulated theoretically with the aid of ChemDraw Ultra 10.0 is shown in Figures 5(a) and 5(b). Table 6 present the predicted chemical shift values of tenofovir obtained by the B3LYP/6-311++G(d,p), B3LYP/6$31 \mathrm{G}(\mathrm{d}, \mathrm{p}), \mathrm{B} 3 \mathrm{PW} 91 / 6-31 \mathrm{G}(\mathrm{d}, \mathrm{p})$ and ChemDraw Ultra 10.0 software package and its assignment along with the shielding values. In general, highly shielded electrons appear downfield and vice versa. The predicted chemical shift values by the theoretical methods both DFT values slightly deviates from the computed values of ChemDraw Ultra. The carbon atom C11 appearing at very higher chemical shift value (177.0 in B3LYP/6-311++G(d,p), 157.1 ppm in B3LYP/6-31G $(\mathrm{d}, \mathrm{p})$ and $152.6 \mathrm{ppm}$ in B3PW91/6-31G(d,p)) due to negative charge of two nitrogen atoms (N10 and N12). Similarly C7, C9, and C13 appearing at higher chemical shift values $(163.5,174.7$ and $166.4 \mathrm{ppm}$ in B3LYP/6-311++G(d,p), 143.3, 155.1 and $144.9 \mathrm{ppm}$ in B3LYP/6-31G(d,p), 141.1, 152.6 and $143.1 \mathrm{ppm}$ in B3PW91/6-31G(d,p)) are due to nitrogen atoms N6, N8, and $\mathrm{N} 15$, respectively.
The carbon atoms C7, C9, C11, C13, and C14 are electropositive and possess more positive charges than the other carbon atoms, and hence the shielding is very small and appears upfield (see Table 6). In both molecules, the DFTcalculated atomic charges revealed that the more electronrich atoms are C1, C3, C4, and C5; they are highly shielded atoms and hence appear at downfield (lower chemical shift). The carbon atoms in the benzene ring are deshielded than the carbon atoms in Aliphatic, so that the benzene carbon atoms in purine appear at higher chemical shift values than the aliphatic carbon atoms that were made by DFT methods. In this study, a good correlation between atomic charges and chemical shift was made. It is to be noted that ${ }^{13} \mathrm{C}$ NMR chemical shifts for tenofovir which agree with the ChemDraw Ultra.

Table 6 gives the ${ }^{1} \mathrm{H}$ NMR predicted chemical shift values obtained by the DFT methods and ChemDraw Ultra 10.0 software program [8] along with assignments. The predicted shielding values for each atom in the tenofovir molecule by B3LYP/6-311++G(d,p), B3LYP/6-31G(d,p), and B3PW91/6$31 \mathrm{G}(\mathrm{d}, \mathrm{p})$ are given in Table 6 . The predicted chemical shift values by the ChemDraw Ultra software program are in good agreement with the two DFT methods.

The spectrum of tenofovir showed a singlet at $7.0 \mathrm{ppm}$ for the proton of the aromatic (H31) group, which is in good agreement with the chemDraw ultra value. Triplet is predicted at 2.9, 2.3, and $2.3 \mathrm{ppm}$ for the methyl group of hydrogen atoms (H25, H26, and H27). This higher chemical shift for methyl group hydrogen is mainly due to the carbon atom (C5). The predicted value of singlet peak at higher chemical shift at $16.2 \mathrm{ppm}$ for methine group of the indole proton (H24). Doublet is predicted at $7.0 \mathrm{ppm}$ for the aromatic group of hydrogen atoms (H30 and H31). This 


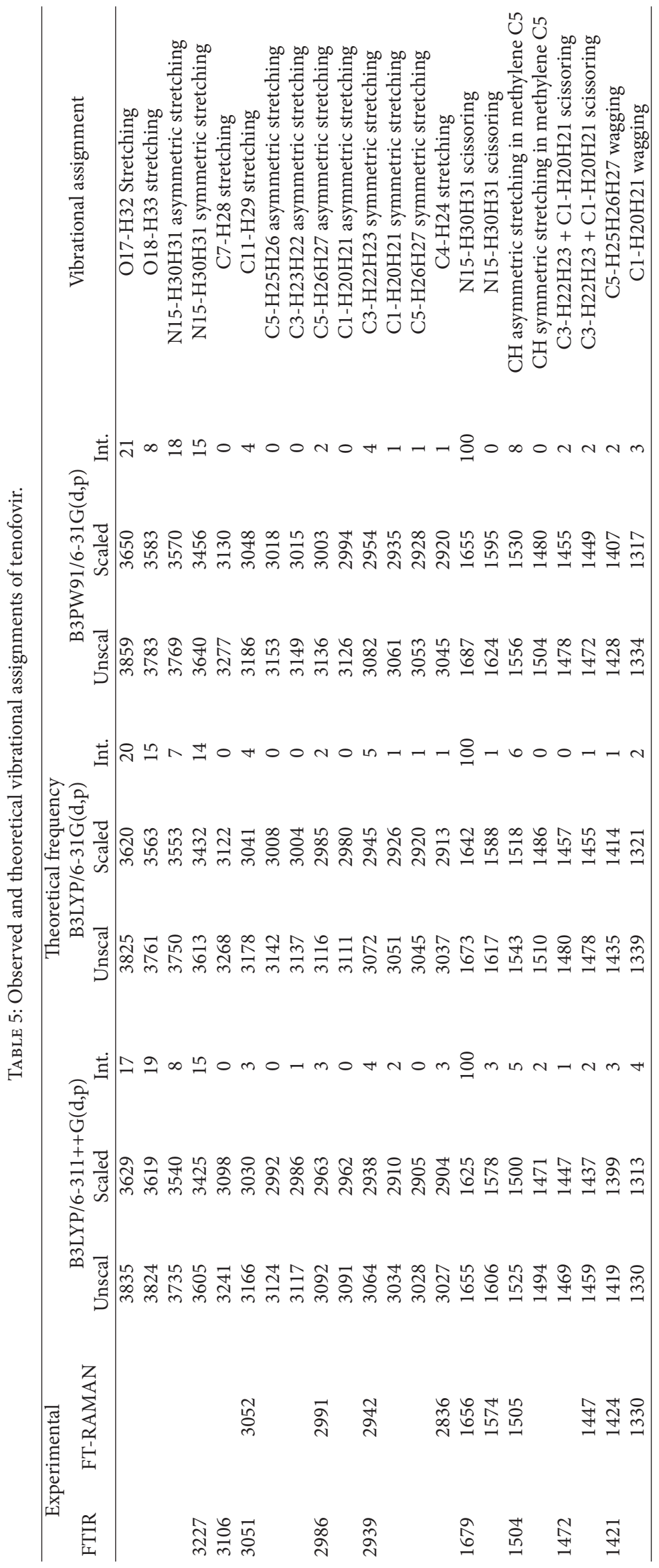


TABLE 6: The calculated ${ }^{13} \mathrm{C}$ and ${ }^{1} \mathrm{H}$ NMR chemical shifts of tenofovir.

\begin{tabular}{|c|c|c|c|c|c|c|c|c|}
\hline \multirow{2}{*}{$\begin{array}{l}\text { Atom } \\
\text { position }\end{array}$} & \multicolumn{2}{|c|}{ B3LYP/6-311++ } & \multicolumn{2}{|c|}{ B3LYP/6-31 } & \multicolumn{2}{|c|}{ B3PW91/6-31 } & \multirow{2}{*}{$\begin{array}{c}\text { ChemDraw } \\
\text { Ultra }\end{array}$} & \multirow[b]{2}{*}{ Assignment } \\
\hline & $\begin{array}{l}\text { Absolute } \\
\text { shielding }\end{array}$ & $\begin{array}{c}\text { Chemical } \\
\text { shift }\end{array}$ & $\begin{array}{l}\text { Absolute } \\
\text { shielding }\end{array}$ & $\begin{array}{c}\text { Chemical } \\
\text { shift }\end{array}$ & $\begin{array}{l}\text { Absolute } \\
\text { shielding }\end{array}$ & $\begin{array}{c}\text { Chemical } \\
\text { shift }\end{array}$ & & \\
\hline 1 & 114.7 & 85.3 & 126.6 & 73.3 & 129.7 & 70.3 & 73.4 & C1 in Aliphatic \\
\hline 3 & 124.7 & 75.3 & 136.6 & 63.4 & 139.3 & 60.7 & 58.6 & C3 in Aliphatic \\
\hline 4 & 122.5 & 77.4 & 134.7 & 65.3 & 137.5 & 62.4 & 76 & C4 in Aliphatic \\
\hline 5 & 153.9 & 46.1 & 163.3 & 36.7 & 166.4 & 33.6 & 20 & C5 in Aliphatic \\
\hline 7 & 36.4 & 163.5 & 56.7 & 143.3 & 58.8 & 141.1 & 143 & C7 in Purine \\
\hline 9 & 25.3 & 174.7 & 44.9 & 155.1 & 47.3 & 152.6 & 149.8 & C9 in Purine \\
\hline 11 & 23.0 & 177.0 & 42.9 & 157.1 & 45.1 & 154.9 & 152.4 & C11 in Purine \\
\hline 13 & 33.6 & 166.4 & 55.0 & 144.9 & 56.9 & 143.1 & 156.1 & C13 in Purine \\
\hline 14 & 62.8 & 137.2 & 81.3 & 118.6 & 83.6 & 116.4 & 119.4 & C14 in Purine \\
\hline 20 & 27.8 & 4.8 & 28.0 & 4.6 & 27.9 & 4.7 & 3.4 & $\mathrm{H} 20$ in Methylene \\
\hline 21 & 27.9 & 4.7 & 28.0 & 4.6 & 28.0 & 4.6 & 3.4 & H21 in Methylene \\
\hline 22 & 27.5 & 5.1 & 27.5 & 5.1 & 27.4 & 5.2 & 3.9 & $\mathrm{H} 22$ in Methylene \\
\hline 23 & 26.8 & 5.8 & 26.7 & 5.9 & 26.6 & 6.0 & 3.7 & H23 in Methyene \\
\hline 24 & 16.4 & 16.2 & 16.3 & 16.3 & 16.2 & 16.4 & 12.0 & H24 in Methine \\
\hline 25 & 29.7 & 2.9 & 29.7 & 2.9 & 29.6 & 3.0 & 1.2 & H25 in Methyl \\
\hline 26 & 30.3 & 2.3 & 30.2 & 2.4 & 30.2 & 2.4 & 1.2 & H26 in Methyl \\
\hline 27 & 30.3 & 2.3 & 30.3 & 2.3 & 30.2 & 2.4 & 1.2 & H27 in Methyl \\
\hline 28 & 23.8 & 8.8 & 23.8 & 8.8 & 23.6 & 9.0 & 8.1 & $\mathrm{H} 28$ in Purine \\
\hline 29 & 23.3 & 9.3 & 23.1 & 9.5 & 22.9 & 9.7 & 8.2 & H29 in Purine \\
\hline 30 & 25.0 & 7.6 & 25.2 & 7.4 & 25.0 & 7.6 & 7.0 & H30 in Aromatic \\
\hline 31 & 25.6 & 7.0 & 25.9 & 6.7 & 25.7 & 6.9 & 7.0 & H31 in Aromatic \\
\hline 32 & 29.2 & 3.4 & 29.0 & 3.6 & 28.9 & 3.7 & 12.0 & H32 in Alcohol \\
\hline 33 & 28.3 & 4.3 & 28.2 & 4.4 & 28.1 & 4.5 & 12.0 & H33 in Alcohol \\
\hline
\end{tabular}

TABLE 7: The calculated thermodynamic parameters of tenofovir.

\begin{tabular}{lccc}
\hline Parameter & B3LYP/6-311++G(d,p) & B3LYP/6-31G(d,p) & B3PW91/6-31G(d,p) \\
\hline Total energy (a.u) & -1267.50 & -1267.25 & -1266.851702 \\
Zero-point energy (Kcal/Mol) & 158.540 & 160.017 & 160.67362 \\
& 0.6560 & 0.7940 & 0.8079 \\
Rotational constants (GHz) & 0.1625 & 0.1463 & 0.1466 \\
& 0.1537 & 0.1368 & 0.1373 \\
Entropy & & & 146.812 \\
Total & 150.214 & 146.784 & 42.862 \\
Translational & 42.862 & 42.862 & 34.246 \\
Rotational & 34.239 & 34.269 & 69.702 \\
Vibrational & 73.113 & 69.653 & 1.6778 \\
Dipole moment (Debye) & 2.3152 & 1.5973 & -6.04 \\
HOMO (eV) & -6.27 & -5.94 & -0.57 \\
LUMO (eV) & -0.95 & -0.51 & 5.46 \\
Energy gap (eV) & 5.31 & 5.43 & \\
\hline
\end{tabular}

higher chemical shift for methyl group hydrogen is mainly due to the nitrogen atom (N15). The hydrogen atoms of methylene group attached with $\mathrm{C} 1$ and $\mathrm{C} 3$ atoms show a multiplet at $3.4-3.9 \mathrm{ppm}$, which is due to the presence of oxygen and nitrogen atoms, respectively. In all the DFT methods predict the chemical shifts value of the hydrogen in hydroxyl group $(\mathrm{H} 32, \mathrm{H} 33)$ is contradicting to chemDraw ultra value, but other hydrogen atoms fairly agrees. 


\section{Thermodynamic Properties}

Several calculated thermodynamic parameters at room temperature are presented in Table 7. According to Koopmanns' theorem, ionization potential (I) is the negative of the highest occupied molecular orbital (HOMO) energy, that is, I = -EHOMO, and affinity potential (A) is the negative of the lowest unoccupied molecular orbital (LUMO) energy, that is, $\mathrm{A}=-$ ELUMO, which are summarized in Table 7.

Knowledge of permanent dipole moment of a molecule provides a wealth of information to determine the exact molecular conformation. The total dipole moment value of tenofovir in both DFTs and B3PW91 methods was observed. The variations in the entropy and zero-point vibrational energies seem to be insignificant.

\section{Conclusion}

The geometry of tenofovir was optimized with both DFT and B3PW91 methods using 6-31G $(\mathrm{d}, \mathrm{p})$ and $6-311++\mathrm{G}(\mathrm{d}, \mathrm{p})$ basis sets. The complete molecular structural parameters and thermodynamic properties of the optimized geometry of the compound have been obtained from DFT calculations. The vibrational frequencies of the fundamental modes of the compound have been precisely assigned and analyzed and the theoretical results were compared with the experimental vibrations. The bond order and atomic charges of the title molecule have been studied by DFT and B3PW91 methods. The energies of important MOs, absorption wavelength $\left(\lambda_{\max }\right)$, oscillator strength, and excitation energies of the compound were also determined from TD-DFT method and compared with the experimental values. This study predicted that the molecular geometry, vibrational wave numbers and ${ }^{13} \mathrm{C}$ and ${ }^{1} \mathrm{H}$ NMR chemical shifts for tenofovir could be successfully elucidated by the B3LYP/6-311++G(d,p), B3LYP/6-31G(d,p) and B3PW91/6-31G(d,p) methods using Gaussian program. Thus, the present investigation provides complete vibrational assignments, structural informations and electronic properties of the compound which may be useful to upgrade the knowledge on tenofovir.

\section{References}

[1] L. Naesens, R. Snoeck, G. Andrei, J. Balzarini, J. Neyts, and E. De Clercq, "HPMPC (cidofovir), PMEA (adefovir) and related acyclic nucleoside phosphonate analogues: a review of their pharmacology and clinical potential in the treatment of viral infections," Antiviral Chemistry \& Chemotherapy, vol. 8, no. 1, pp. 1-23, 1997.

[2] M. Arimilli, C. Kim, and N. Bischofberger, "Synthesis, in vitro biological evaluation and oral bioavailability of 9-[2-(phosphonomethoxy)propyl]adenine (PMPA) prodrugs," Antiviral Chemistry \& Chemotherapy, vol. 8, no. 6, pp. 557-564, 1997.

[3] L. Naesens, N. Bischofberger, P. Augustijns et al., "Antiretroviral efficacy and pharmacokinetics of oral bis(isopropyloxycarbonyloxymethyl)-9-(2-phosphonylmethoxypropyl)adenine in mice," Antimicrobial Agents and Chemotherapy, vol. 42, no. 7, pp. 1568-1573, 1998.
[4] J. Balzarini, A. Holy, J. Jindrich et al., "Differential antiherpesvirus and antiretrovirus effects of the (S) and (R) enantiomers of acyclic nucleoside phosphonates: potent and selective in vitro and in vivo antiretrovirus activities of (R)9-(2-phosphonomethoxypropyl)- 2,6-diaminopurine," Antimicrobial Agents and Chemotherapy, vol. 37, no. 2, pp. 332-338, 1993.

[5] B. L. Robbins, R. V. Srinivas, C. Kim, N. Bischofberger, and A. Fridland, "Anti-human immunodeficiency virus activity and cellular metabolism of a potential prodrug of the acyclic nucleoside phosphonate 9-R-(2- phosphonomethoxypropyl)adenine (PMPA), bis(isopropyloxymethylcarbonyl)PMPA," Antimicrobial Agents and Chemotherapy, vol. 42, no. 3, pp. 612-617, 1998.

[6] B. L. Robbins, J. J. Greenhaw, M. C. Connelly, and A. Fridland, "Metabolic pathways for activation of the antiviral agent 9-(2phosphonylmethoxyethyl)adenine in human lymphoid cells," Antimicrobial Agents and Chemotherapy, vol. 39, no. 10, pp. 2304-2308, 1995.

[7] V. Miller and B. A. Larder, "Mutational patterns in the HIV genome and cross-resistance following nucleoside and nucleotide analogue drug exposure," Antiviral Therapy, vol. 6, supplement 3, pp. 25-44, 2001.

[8] Carl Kemnitz 2002 Chemoffice ultra 10, Trial version.

[9] M. J. Frisch, G. W. Trucks, H. B. Schlegel et al. Gaussian Inc., Woodbridge, Conn, USA, 2004.

[10] H. B. Schlegel, "Optimization of equilibrium geometries and transition structures," Journal of Computational Chemistry, vol. 3, no. 2, pp. 214-218, 1982.

[11] A. D. Becke, "Density-functional exchange-energy approximation with correct asymptotic behavior," Physical Review A, vol. 38, no. 6, pp. 3098-3100, 1988.

[12] C. Lee, W. Yang, and R. G. Parr, "Development of the ColleSalvetti correlation-energy formula into a functional of the electron density," Physical Review B, vol. 37, no. 2, pp. 785-789, 1988.

[13] B. G. Johnson and M. J. Frisch, "Analytic second derivatives of the gradient-corrected density functional energy. Effect of quadrature weight derivatives," Chemical Physics Letters, vol. 216, no. 1-2, pp. 133-140, 1993.

[14] K. Burke, J. P. Perdew, and Y. Wang, "Derivation of a generalized gradient approximation: the PW91 density functional," in Electronic Density Functional Theory; Recent Progress and New Directions, J. F. Dobson, G. Vignale, and M. P. Das, Eds., Plenum Press, 1998.

[15] J. P. Perdew, "Unified theory of exchange and correlation beyond the local density approximation," in Electronic Structure of Solids '91, P. Ziesche and H. Eschrig, Eds., pp. 11-20, Academic Verlag, Berlin, Germany, 1991.

[16] J. P. Perdew, J. A. Chevary, S. H. Vosko et al., "Atoms, molecules, solids, and surfaces: applications of the generalized gradient approximation for exchange and correlation," Physical Review $B$, vol. 46, no. 11, pp. 6671-6687, 1992.

[17] J. P. Perdew, J. A. Chevary, S. H. Vosko et al., "Erratum: atoms, molecules, solids, and surfaces: applications of the generalized gradient approximation for exchange and correlation," Physical Review B, vol. 48, no. 7, p. 4978, 1993.

[18] J. P. Perdew, K. Burke, and Y. Wang, "Generalized gradient approximation for the exchange-correlation hole of a manyelectron system," Physical Review B, vol. 54, no. 23, pp. 16533-16539, 1996. 
[19] J. P. Perdew and Y. Wang, "Accurate and simple analytic representation of the electron-gas correlation energy," Physical Review B, vol. 45, no. 23, pp. 13244-13249, 1992.

[20] W. J. Hehre, L. Radom, P. V. R. Schleyer, and A. J. Pople, Ab Initio Molecular Orbital Theory, John Wiley \& Sons, New York, NY, USA, 1989.

[21] Z. Dega-Szafran, A. Katrusiak, and M. Szafran, "Molecular structure of the complex of $N$-methylmorpholine betaine with 2,4-dinitrophenol," Journal of Molecular Structure, vol. 741, no. 1-3, pp. 1-9, 2005.

[22] S. I. Gorelsky, SWizard program, 2005, http://www.sg-chem .net/.

[23] H. B. Schlegel, "An efficient algorithm for calculating ab initio energy gradients using s, p Cartesian Gaussians," The Journal of Chemical Physics, vol. 77, no. 7, pp. 3676-3681, 1982.

[24] S. A. Ghorpade, M. S. Sali, A. H. Kategaonkar, D. M. Patel, V. P. Choudhari, and B. S. Kuchekar, "Simultaneous determination of emtricitabine and tenofovir by area under curve and dual wavelength spectrophotometric method," Journal of the Chilean Chemical Society, vol. 55, no. 1, pp. 115-117, 2010.

[25] R. M. Silverstein, G. C. Bassler, and T. C. Morrill, Spectrometric Identification of Organic Compounds, John Wiley \& Sons, New York, NY, USA, 5th edition, 1981.

[26] H. Yoshida, K. Takeda, J. Okamura, A. Ehara, and H. Matsuura, "A new approach to vibrational analysis of large molecules by density functional theory: wavenumber-linear scaling method," Journal of Physical Chemistry A, vol. 106, no. 14, pp. 3580-3586, 2002.

[27] R. A. Yadav and I. S. Sing, "Hydrogen bonding in o- and m-ethyl phenols," Indian Journal of Pure and Applied Physics, vol. 23, pp. 626-627, 1985.

[28] K. B. Wibery and A. Shrake, "A vibrational study of cyclohexane and some of its isotopic derivatives-III. A vibrational analysis of cyclohexane, cyclohexane- $d_{12}$, cyclohexane-1,1,4,4- $d_{4}$ and cyclohexane-1,1,2,2,4,4,5,5- $d_{8}$," Spectrochimica Acta A, vol. 29, no. 3, pp. 583-594, 1973. 

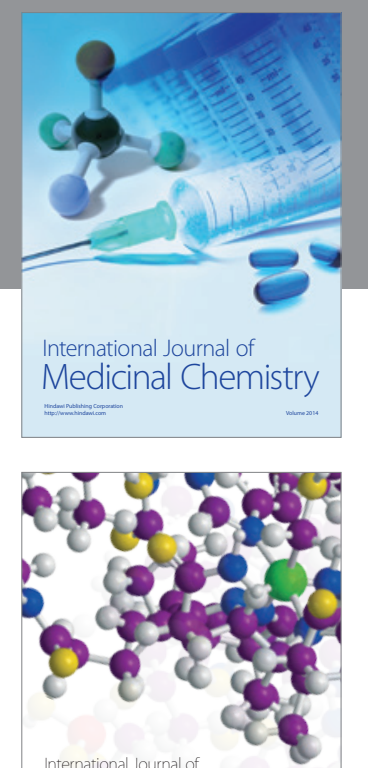

\section{Carbohydrate} Chemistry

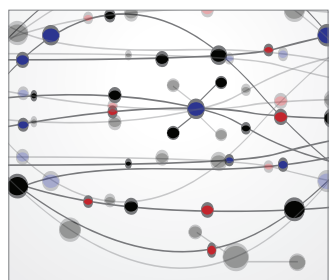

The Scientific World Journal
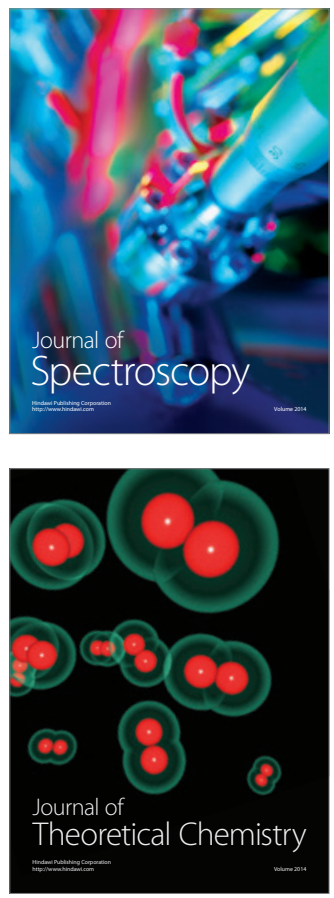
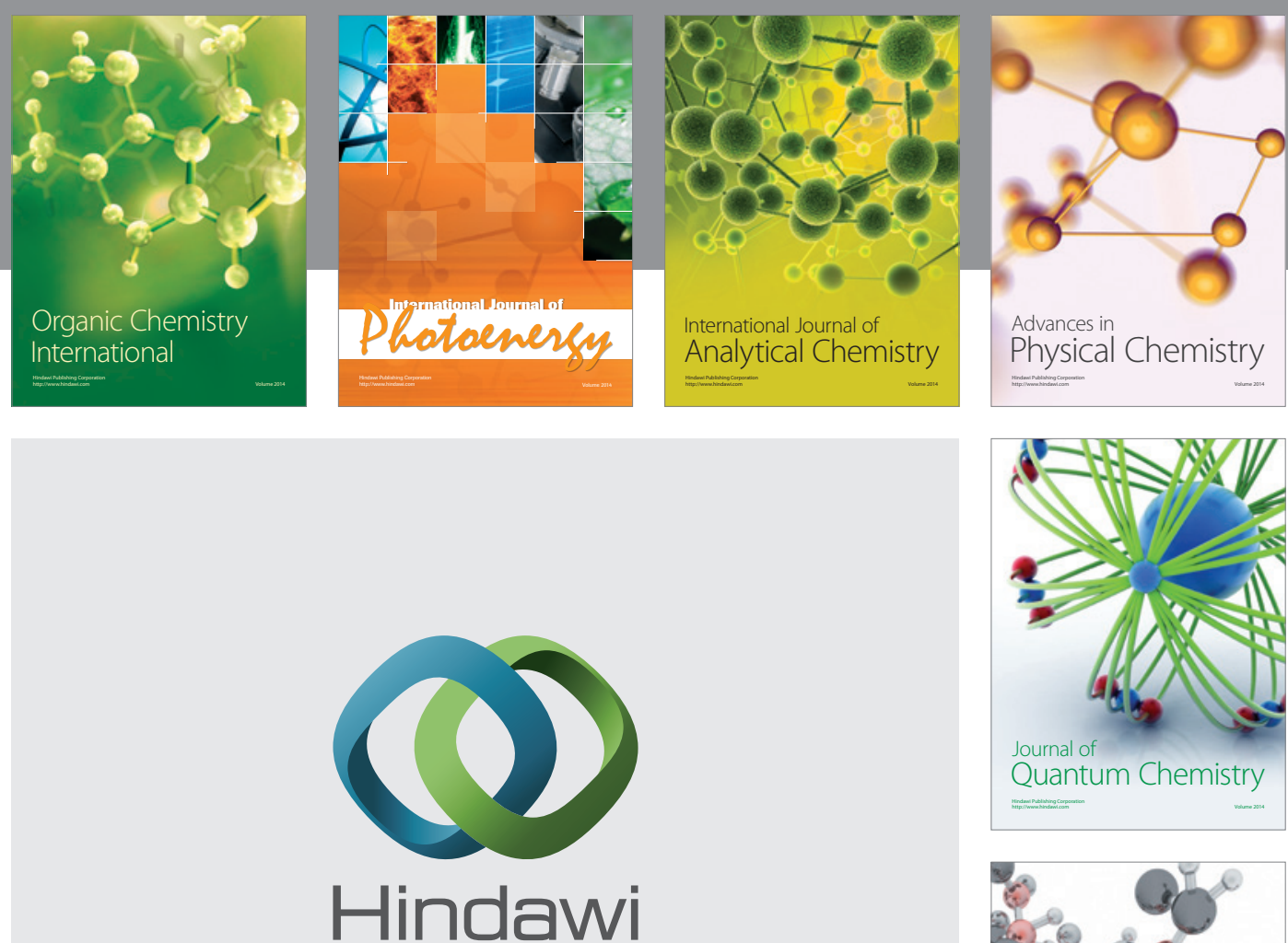

Submit your manuscripts at

http://www.hindawi.com

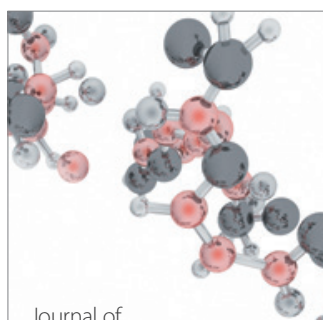

Analytical Methods

in Chemistry

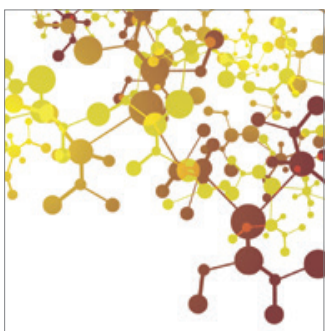

Journal of

Applied Chemistry

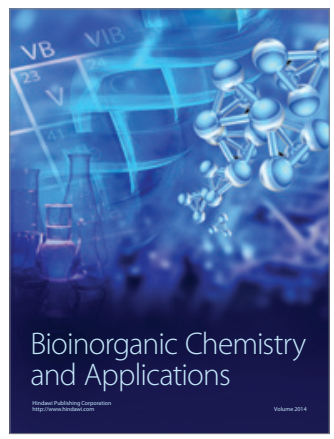

Inorganic Chemistry
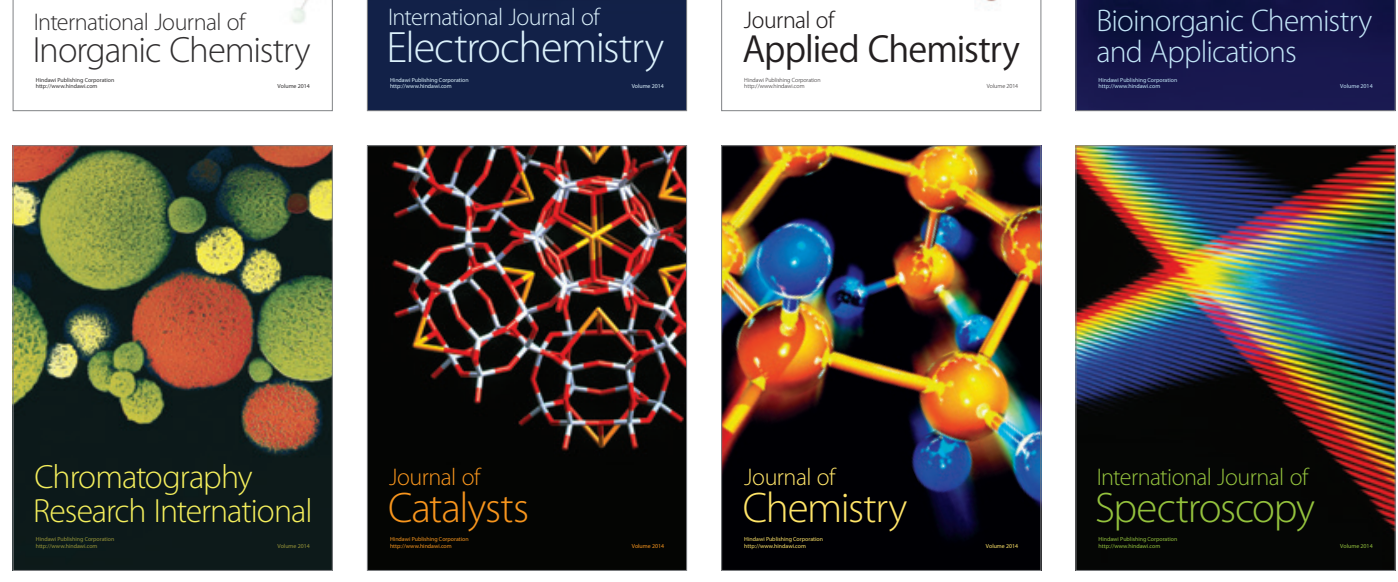